\title{
Self-harm in adolescents: self-report survey in schools in Scotland
}

Rory C. O'Connor, Susan Rasmussen, Jeremy Miles and Keith Hawton

\section{Background}

The suicide rate in Scotland is twice as high as that in England. However, the prevalence of self-harm is unknown.

\section{Aims}

To determine the prevalence of self-harm in adolescents in scotland and the factors associated with it

\section{Method}

A total of 2008 pupils aged $15-16$ years completed an anonymous lifestyle and coping survey. Information was obtained on demographic characteristics, lifestyle, life events and problems, social influences, psychological variables and self-harm.

\section{Results}

Self-harm was reported by $13.8 \%$ of the respondents. The majority $(71 \%)$ of those who had self-harmed had done so in the past 12 months and girls were approximately 3.4 times more likely to report self-harm than boys. In multivariate analyses, smoking, bullying, worries about sexual orientation, self-harm by family and anxiety were associated with selfharm in both genders. In addition, drug use, physical abuse, serious boy/girlfriend problems, self-harm by friends and low levels of optimism were also associated with self-harm in girls.

\section{Conclusions}

Despite markedly different national suicide rates, the prevalence of self-harm in Scotland is similar to that in England with girls at least three times more likely to report self-harm than boys. The findings suggest a role for emotional literacy programmes in schools and highlight the importance of promoting positive mental health among adolescents.

\section{Declaration of interest}

None. Funding detailed in Acknowledgements.
In recent years there has been considerable research interest in determining the prevalence of self-harm among adolescents. ${ }^{1-3}$ This is not surprising as self-harm is a key predictor of completed suicide ${ }^{4,5}$ and suicide prevention is a high priority for UK governments. ${ }^{6,7}$ In an attempt to identify the prevalence of self-harm among adolescents, several countries including England developed and completed the Child and Adolescent Self-harm in Europe (CASE) questionnaire. ${ }^{8}$ Comparative analyses of the cross-national CASE questionnaires found that five of the countries (England, Ireland, Belgium, Norway and Australia) reported similar self-harm rates, whereas The Netherlands and Hungary reported relatively low rates. ${ }^{8}$ Closer inspection of the responses to the English CASE questionnaire showed that the selfreported lifetime prevalence of self-harm among young people in England aged 15-16 years was $13.2 \%$. The CASE questionnaires report both self-reported self-harm and self-harm that meets specific CASE study criteria. To afford direct comparison with the Scotland data presented herein, we have concentrated on the former. Given that the suicide rate in Scotland is the highest in the UK and is twice as high as that in England, ${ }^{9,10}$ the central aim of our study was to determine, for the first time, the prevalence of adolescent self-harm in Scotland. Scotland is of special interest because not only do England and Scotland have markedly different suicide rates, they have distinct suicide rate trends: Scotland's suicide rate has been increasing in recent decades whereas England's has been decreasing, with England last year reporting its lowest suicide rate on record. ${ }^{9-11}$ The utility of such a comparative study is further highlighted by a recent study of adolescent self-harm in two neighbouring European countries: The Netherlands and Belgium. ${ }^{12}$ Portzky et al, employing the CASE questionnaire, found that the adolescent self-harm rate in Belgium was markedly higher than that in The Netherlands, consistent with the countries' different suicide rates (the Belgian suicide rate is much higher than the Dutch rate). ${ }^{12}$ Our second aim was to examine the factors associated with adolescent selfharm. For this purpose we modified the CASE questionnaire and included additional psychosocial factors known to be important in the aetiology of self-harm and suicidal behaviour. ${ }^{13-15}$

\section{Method}

All secondary schools in Glasgow (west Scotland) and Stirling (central Scotland) were invited to participate in the study (45 schools). Thirteen schools agreed to participate and this yielded a representative sample in terms of school type for size, status, ethnic minorities, educational attainment and socio-economic deprivation (proportion of pupils entitled to free school meals). We recruited $29 \%$ of the target schools to the study, consistent with Hawton et al who recruited 24\%. ${ }^{1}$ Data were collected during 2006-7. All pupils were in secondary years S4 or S5 and in classes in which at least $90 \%$ of the young people were aged $15-16$ years.

\section{Procedure}

The aim of the study was explained to the head teachers or their designates. Parents were informed of the project by letter and asked to notify the school if they did not want their child to participate. Two or three weeks before data collection, the nature of participation was explained in detail to the teachers. On the day of participation pupils were given the choice of opting out and not participating.

We had obtained ethical approval from the University of Stirling Psychology Department ethics committee. Our study adhered to the British Psychological Society's ethical guidelines and the British Educational Research Association's guidelines. ${ }^{16,17}$ To highlight that the survey was anonymous, all pupils were provided with an envelope into which to insert and seal their completed questionnaires. The sealed envelopes were opened only 
by members of the research team. Each participant was also given an information sheet to take away, which included telephone, postal and electronic contacts for useful support organisations.

\section{Assessment of participants}

A modified version of the CASE questionnaire was used. It is an anonymous self-report questionnaire, taking approximately $30 \mathrm{~min}$ to complete. The original survey was developed in collaboration with experts in school-based studies and it incorporated extensive piloting in schools and in an adolescent psychiatric unit. The questionnaire included items on demographic characteristics (gender, age, ethnicity), lifestyle, life events and problems, social influences, psychological variables and self-harm. Self-harm was recorded if a respondent answered 'yes' to the following question: 'Have you ever deliberately taken an overdose (e.g. pills or other medication) or tried to harm yourself in some other way (such as cut yourself)?' Respondents were also asked to provide a description of the act, its consequences and to endorse the motive behind the act. For the study's main analyses we did not use the description to classify the act as self-harm because excluding those who chose not to write a description might yield an underestimate of prevalence, as some respondents deemed describing the act as too personal and painful; the vast majority of descriptions yielded a self-harm classification according to Hawton \& Rodham's classification guidelines, ${ }^{8}$ and all but three of those who gave a positive answer to the self-harm question either provided a description or endorsed a self-harm motive. However, in the interests of completeness, we report the frequencies of those whose self-harm episode met the CASE criteria. These criteria define self-harm as follows:

'[an] act with a non-fatal outcome in which an individual deliberately did one or more of the following: initiated behaviour (e.g. self-cutting, jumping from a height), which they intended to cause self-harm; ingested a substance in excess of the prescribed or generally recognised therapeutic dose; ingested a recreational or illicit drug that was an act the person regarded as self-harm; ingested a non-ingestible substance or object.' (p. 29)

Other questionnaire items included measures of depression and anxiety (the Hospital Anxiety and Depression Scale), ${ }^{18}$ impulsivity (six items from the Plutchick Impulsivity Scale), ${ }^{19}$ selfesteem (an eight-item version of the Self-Concept Scale), ${ }^{20}$ peer group norms (i.e. the attitudes of peers and friends towards selfharm), ${ }^{21}$ trait optimism (the revised Life Orientation Scale), ${ }^{22}$ and social perfectionism (defined as the degree of belief that others hold unrealistically high expectations of one's behaviour and that they would only be satisfied with these standards). ${ }^{23}$ Full details of all the questions in the questionnaire are available from the author.

\section{Sample size and analyses}

We chose a sample size of 2000 pupils assuming a prevalence estimate of $12 \%$ for young people reporting self-harm, based on previous studies in England, Ireland and Australia. ${ }^{1,2,24}$ This sample size can detect an effect with $80 \%$ power and $5 \%$ significance with a $95 \%$ confidence interval (CI) of $10.7-13.5 \%{ }^{25}$ Logistic regression analyses and chi-squared tests were used to investigate the association between self-harm and associated variables. Crude odds ratios (ORs) and CIs were obtained from the univariate logistic regression analyses. Adjusted ORs were obtained from multivariate logistic regression. Backward selection was used to determine the factors that were most important statistically in distinguishing the presence or absence of a selfharm history. We analysed the data using SPSS version 14.0 for Windows.

\section{Results}

Of the 13 participating schools, 10 were local authority/comprehensive schools and 3 were independently funded. In total, 2008 young people participated in the study: this represented approximately $80 \%$ of those eligible to participate. The main reasons for non-participation were timetable constraints (which meant that not all classes in a given school year group were able to complete the survey) and absenteeism. Consistent with the 2001 UK census, $92 \%$ of the sample were White, $5.3 \%$ were Asian, $1.5 \%$ Black and $1.2 \%$ of other ethnicity. Slightly more than half $(53 \%)$ of the sample were girls (Table 1).

\section{Prevalence of self-harm}

Almost 14\% (13.8\%) of the sample reported a lifetime history of self-harm (i.e. presence of self-harm history) and the majority of those had self-harmed in the previous 12 months $(71 \%, 190 /$ 268; 4 participants did not provide a response, see Table 1); $10.4 \%$ (6.1\% girls, $14.3 \%$ boys) of the respondents reported a lifetime history of self-harm that met the CASE criteria (data not presented). All proceeding analyses are based on the former group (i.e. all those who reported self-harm). Girls were 3.4 times more likely to report self-harm than boys $(\mathrm{OR}=3.37,95 \%$ CI $2.50-4.54$, $P<0.001)$. Half ( $n=137,52.9 \%)$ had started to think about selfharm less than an hour before the act; $15.1 \%(n=39)$ more than an hour but less than a day before; $12.7 \%(n=33)$ more than a day but less than a week before; and $19.3 \%(n=50)$ more than a week beforehand. The main motive for self-harm was to 'get relief from a terrible state of mind' $(74.5 \%, n=175)$, followed by

Table 1 Prevalence of self-harm (past year and lifetime) and serious thoughts of self-harm in the previous year

\begin{tabular}{|c|c|c|c|}
\hline & $\begin{array}{c}\text { Respondents } \\
n\end{array}$ & $\begin{array}{l}\text { Prevalence } \\
\quad \%(n)\end{array}$ & Odds ratio $(95 \% \mathrm{Cl})$ \\
\hline \multicolumn{4}{|c|}{ Past year prevalence of self-harm } \\
\hline Boys & 917 & $5.1(47)$ & 1.00 \\
\hline Girls & 1050 & $13.6(143)$ & $2.94(2.09-4.14)$ \\
\hline All ${ }^{a}$ & 1967 & $9.7(190)$ & \\
\hline \multicolumn{4}{|c|}{ Lifetime prevalence of self-harm } \\
\hline Boys & 917 & $6.9(63)$ & 1.00 \\
\hline Girls & 1050 & $19.9(209)$ & $3.37(2.50-4.54)$ \\
\hline All ${ }^{\mathrm{a}}$ & 1967 & $13.8(272)$ & \\
\hline \multicolumn{4}{|c|}{ Serious thoughts of self-harm in past year without doing so } \\
\hline Boys & 913 & $8.5(78)$ & 1.00 \\
\hline Girls & 1052 & $19.5(205)$ & $2.59(1.96-3.42)$ \\
\hline All ${ }^{a}$ & 1965 & $14.4(283)$ & \\
\hline
\end{tabular}


'wanting to punish oneself' $(51.9 \%, n=109)$. Almost four in ten adolescents reported that they wanted to die $(37.6 \%, n=77)$. Reports of seriously thinking about taking an overdose or trying to harm oneself but not actually doing so were more common in girls than boys (Table 1; OR=2.59, 95\% CI 1.96-3.42, $P<0.001)$. Owing to missing data, there is some variability in the denominator across the variables (online Table DS1).

\section{Factors associated with self-harm}

Given the established gender differences in self-harm, ${ }^{3,26}$ the subsequent analyses are presented separately for boys and girls. For female participants, living with one parent or one parent and one step-parent was associated with increased risk of selfharm compared with living with both parents (Table DS1). More girls whose parents had divorced reported self-harm compared with those whose parents had not divorced. On the whole, increased consumption of alcohol and cigarettes was associated with more self-harm in boys and girls, as was the frequency of getting drunk in the previous year. Drug taking was associated with selfharm in girls only. For both genders, lifetime prevalence of being bullied at school, physical abuse, sexual abuse, worries about one's sexual orientation, being in trouble with the police and reporting serious problems with a boy/girlfriend were strongly related to self-harm. The sexual and physical abuse questions asked whether the respondent had been abused; they did not record by whom. Social influences on self-harm were also evident: for all pupils, self-harm by family and friends was associated with increased frequencies of self-harm, as were increased group norms for self-harm. Finally, those who had self-harmed, irrespective of gender, were more depressed, anxious, impulsive and social perfectionists, as well as reporting lower self-esteem and lower optimism, than those who had not self-harmed.

\section{Multivariate analysis}

Multivariate logistic analysis showed that the following factors were independently associated with self-harm in girls: smoking, drug use, bullying, physical abuse, worries about sexual orientation, serious boy/girlfriend problems, self-harm by family and friends and anxiety (Table 2). Optimism was also lower among girls who self-harmed. In boys, smoking, bullying, sexual orientation worries, self-harm in the family, group norms and anxiety were associated with self-harm.

\section{Discussion}

Self-harm is common among adolescents in Scotland, especially among girls. Indeed, the prevalence of self-harm in Scotland is similar to that reported in England, ${ }^{1}$ Ireland, ${ }^{24}$ Belgium, ${ }^{12}$ Norway, ${ }^{27}$ Australia $^{2}$ and the USA, ${ }^{28}$ but higher than that reported in The Netherlands ${ }^{12}$ and Hungary. ${ }^{29}$ Despite Scotland having the

Table 2 Multivariate logistic regression for lifetime prevalence of self-harm

\begin{tabular}{|c|c|c|c|c|c|c|}
\hline & \multicolumn{3}{|c|}{ Girls } & \multicolumn{3}{|c|}{ Boys } \\
\hline & Odds ratio & $95 \% \mathrm{Cl}$ & $P$ & Odds ratio & $95 \% \mathrm{Cl}$ & $P$ \\
\hline \multicolumn{7}{|l|}{ Smoking ${ }^{a}$} \\
\hline Never & 1.00 & & & 1.00 & & \\
\hline Given up & 3.43 & $1.87-6.29$ & $<0.001$ & 1.73 & $0.52-5.72$ & NS \\
\hline Up to 5 & 2.01 & $0.74-5.47$ & NS & 11.00 & $2.87-42.18$ & $<0.001$ \\
\hline $6-20$ & 2.06 & $1.01-4.21$ & $<0.05$ & 7.74 & $2.66-22.51$ & $<0.001$ \\
\hline $21-50$ & 2.36 & $1.03-5.41$ & $<0.05$ & 2.65 & $0.32-21.97$ & NS \\
\hline$>50$ & 1.56 & $0.43-5.70$ & NS & 3.40 & $0.96-12.02$ & NS \\
\hline \multicolumn{7}{|l|}{ Drug use ${ }^{b}$} \\
\hline No & 1.00 & & & & & \\
\hline Yes & 1.95 & $1.19-3.18$ & $<0.01$ & & & \\
\hline \multicolumn{7}{|l|}{ Bullying in schoolc } \\
\hline No & 1.00 & & & 1.00 & & \\
\hline Yes & 3.09 & $2.06-4.64$ & $<0.001$ & 2.18 & $1.11-4.28$ & $<0.05$ \\
\hline \multicolumn{7}{|l|}{ Physical abuse ${ }^{c}$} \\
\hline No & 1.00 & & & & & \\
\hline Yes & 2.15 & $1.02-4.53$ & $<0.05$ & & & \\
\hline \multicolumn{7}{|c|}{ Sexual orientation worries ${ }^{c}$} \\
\hline No & 1.00 & & & 1.00 & & \\
\hline Yes & 2.57 & $1.28-5.20$ & $<0.01$ & 3.82 & $1.53-9.50$ & $<0.005$ \\
\hline \multicolumn{7}{|c|}{ Serious boy/girlfriend problems ${ }^{c}$} \\
\hline No & 1.00 & & & & & \\
\hline Yes & 2.30 & $1.53-3.46$ & $<0.001$ & & & \\
\hline \multicolumn{7}{|c|}{ Self-harm by friends ${ }^{c}$} \\
\hline No & 1.00 & & & & & \\
\hline Yes & 2.89 & $1.94-4.29$ & $<0.001$ & & & \\
\hline \multicolumn{7}{|c|}{ Self-harm by familyc } \\
\hline No & 1.00 & & & 1.00 & & \\
\hline Yes & 2.19 & $1.38-3.47$ & $<0.001$ & 8.85 & $4.38-17.90$ & $<0.001$ \\
\hline Group norms ${ }^{\mathrm{d}, \mathrm{e}}$ & & & & 1.15 & $1.04-1.28$ & $<0.01$ \\
\hline Optimism ${ }^{\text {d }}$ & 0.93 & $0.88-0.97$ & $<0.005$ & & & \\
\hline Anxiety $^{d}$ & 1.13 & $1.06-1.19$ & $<0.001$ & 1.17 & $1.07-1.27$ & $<0.001$ \\
\hline \multicolumn{7}{|c|}{$\begin{array}{l}\text { a. Number of cigarettes smoked in a typical week. } \\
\text { b. Past year prevalence. } \\
\text { c. Lifetime prevalence. } \\
\text { d. Odds ratio for } 1 \text { point increase in score (higher scores indicate higher depression, anxiety, impulsivity, self-esteem, optimism and social perfectionism). } \\
\text { e. Higher scores indicate more positive group norms for self-harm. }\end{array}$} \\
\hline
\end{tabular}


highest suicide rate in the UK, its adolescent self-harm rates do not follow this trend. Indeed, the similarity of adolescent selfharm with that in England is especially noteworthy because the suicide rate in Scotland is twice that in England. ${ }^{9-11}$ The absence of an English-Scottish difference is also interesting in the light of the Belgium-Netherlands comparative study which found that their cross-national self-harm rates were consistent with their respective completed suicide rates. ${ }^{12}$ Perhaps the sociocultural effects in England and Scotland are diluted because both countries are part of the UK. Future research should explore these national sociocultural effects more closely. In addition, it would be of interest to investigate further whether suicidal self-harm rates differ in Scotland and England. Indeed, it may be that the rates of medically serious self-harm (e.g. overdose) closely mirror the completed suicide rates by country, whereas non-suicidal self-harm rates do not. Alternatively, it may be that some national rates of self-destructive behaviours only begin to differ from the late teenage years onwards when such behaviours become more common. There is also a substantial number of young people $(14.4 \%)$ who seriously think about self-harm but who do not do so.

We endeavoured to obtain a 'true' picture of the prevalence of self-harm by highlighting to respondents that we were an independent research team, by providing all respondents with an envelope in which to deposit and seal their completed questionnaire and by ensuring that the respondents completed the items in the questionnaire in different orders (such counterbalancing precluded pupils 'checking' how their neighbour was responding). Despite endeavouring to include as many young people as possible from the target population in the survey ( $80 \%$ of the target sample took part), we cannot rule out the impact of absenteeism on the prevalence of self-harm, as it is known that self-harm is more common in those who truant (therefore adjusting for truancy would increase the 'true' prevalence rate for self-harm). ${ }^{30}$

Consistent with similar studies in other countries, ${ }^{1,2,24}$ the results highlight the powerful effects of social influences and therefore the need to give careful attention to the management of self-harm in schools and in young people's lives more widely. For both genders, self-harm by family and friends was strongly associated with self-harm. Although self-harm by friends did not emerge as a significant independent factor in boys, this is possibly a statistical artefact, accounted for by the variance shared with the male group norms variable (group norms are defined as the beliefs, attitudes and behaviour of male respondents' friends and peers, in this case suggesting that self-harm is desirable).

Although we cannot infer causality from a cross-sectional survey, the findings highlight a number of key factors that are independently associated with self-harm. Indeed, future research is urgently required to determine the mechanisms linking the social influence effects to self-harm. Are these influences indicative of modelling or clustering effects (two phenomena widely reported in the research literature) $?^{31,32}$ Indeed, the familial intergenerational transmission of suicide risk is noted elsewhere. ${ }^{33}$ Bullying and sexual orientation worries, consistent with work in other countries, also emerged as key correlates of self-harm and their management requires urgent consideration for boys and girls. $^{34,35}$ Despite being associated with self-harm in both genders in the univariate analyses, it is worth highlighting that impulsivity did not emerge as a risk factor in the multivariate analysis. This is of particular importance given that more than half the sample reported that they had thought about self-harming less than an hour before doing so. Depression also did not emerge as an independent risk factor. This may be explained in part by the inclusion of optimism, as post hoc analyses suggest that the latter partially mediates the relationship between depression and selfharm. The motives for self-harm reported by the young people merit comment. Consistent with the English findings, ${ }^{1}$ the most common motivation reported by Scottish adolescents was 'to get relief from a terrible state of mind' - highlighting that, for the most part, the common motives underpinning self-harm are not predominantly manipulative in nature. Almost one in four young people reported that they wanted to die. Future interview-based research could usefully explore this motive further to determine whether such young people do indeed wish to end their lives.

This is one of the first studies to investigate formally the relationship between trait optimism and self-harm. Trait optimism is broadly defined as exhibiting generalised positive expectancies for the future; optimists are characterised as having greater confidence in their ability to attain goals, being better at identifying suitable goals and being more tenacious with respect to goal pursuit. $^{13,14}$ Indeed, school-based interventions aimed at improving optimism ought to be evaluated to determine whether they protect against self-harm among girls. In addition, the promotion of mental health, the development (and evaluation) of emotional literacy programmes and initiatives that focus on responding to bullying, physical abuse, sexual orientation worries and interpersonal problems as well as managing anxiety may offer promise. The findings of this survey could also form the basis for screening programmes to aid teachers in the identification of those at risk.

\section{Rory C. O'Connor, Susan Rasmussen, Suicidal Behaviour Research Group, University of Stirling, UK; Jeremy Miles, RAND Corporation, Santa Monica, California, USA; Keith Hawton, Centre for Suicide Research, University Department of Psychiatry, Warneford Hospital, Oxford, UK}

Correspondence: Professor R. O'Connor, Suicidal Behaviour Research Group, University of Stirling, Stirling FK9 4LA, UK. Email: ro2@stir.ac.uk

First received 21 Nov 2007, final revision 19 May 2008, accepted 13 Aug 2008

\section{Acknowledgements}

This study was part-funded by Choose Life Stirling (national suicide prevention strategy for scotland) and the University of Stirling.

\section{References}

1 Hawton K, Rodham K, Evans E, Weatherall R. Deliberate self-harm in adolescents: self-report survey in schools in England. BMJ 2002; 325: 1207-11.

2 De Leo D, Heller TS. Who are the kids who self-harm? An Australian selfreport school survey. Med J Aust 2004; 181: 140-4.

3 Centers for Disease Control and Prevention. Youth risk behavior surveillance - United States, 2003. MMWR Morb Mortal Wkly Rep 2004; 53 (SSO2): 1-96.

4 O'Connor R, Sheehy, N. Understanding Suicidal Behaviour. Blackwell, 2000.

5 Hawton K, Houston K, Shepperd R. Suicide in young people: a study of 174 cases, aged under 25 years, based on coroners' and medical records. Br J Psychiatry 1999; 175: 271-6.

6 Department of Health. Suicide Prevention Strategy for England. HMSO, 2002.

7 Scottish Executive. Choose Life. The National Suicide Prevention Strategy and Action Plan. HMSO, 2002.

8 Hawton K, Rodham K. By Their Own Hand. Deliberate Self-Harm and Suicidal Ideas in Adolescents. Jessica Kingsley, 2006.

9 Platt S, McLean J, McCollam A, Blamey A, Mackenzie M, McDaid D, et al. Evaluation of the First Phase of Choose Life: The National Strategy and Action Plan to Prevent Suicide in Scotland. Scottish Executive Social Research, 2006.

10 Brock A, Baker A, Griffiths C, Jackson G, Fegan G, Marshall D. Suicide trends and geographical variations in the United Kingdom, 1991-2004. Health Stat $Q$ 2006; 31: 6-22.

11 National Institute for Mental Health for England. National Suicide Prevention Strategy for England. Annual Report on Progress 2006. NIMH, 2007. 
12 Portzky G, De Wilde E-J, van Heeringen K. Deliberate self-harm in young people: differences in prevalence and risk factors between The Netherlands and Belgium. Eur Child Adolesc Psychiatry 2008; 17: 179-86.

13 Carver CS, Scheier MF. On the Self-Regulation of Behavior. Cambridge University Press, 1998.

14 O'Connor RC, Whyte MC, Fraser L, Masterton G, Miles J, MacHale S. Predicting short-term outcome in well-being following suicidal behaviour: the conjoint effects of social perfectionism and positive future thinking. Behav Res Ther 2007; 45: 1543-55.

15 O'Connor RC, Cassidy C. Predicting hopelessness: the interaction between optimism/pessimism and specific future expectancies. Cogn Emot 2007; 21 596-613.

16 British Educational Research Association. Ethical Guidelines for Educational Research. BERA, 1992.

17 British Psychological Society. Guidelines for Minimum Standards of Ethical Approval in Psychological Research. BPS, 2004.

18 White D, Leach R, Sims R, Atkinson M, Cottrell D. Validation of the Hospita Anxiety and Depression Scale for use with adolescents. Br J Psychiatry 1999; 175: $452-4$

19 Plutchick R, van Praag HM, Picard S, Conte HR, Korn M. Is there a relation between the seriousness of suicidal intent and the lethality of the suicide attempt? Psychiatry Res 1989; 27: 71-9.

20 Robson P. Development of a new self-report questionnaire to measure selfesteem. Psychol Med 1989; 19: 513-8.

21 O'Connor RC, Armitage CJ, Gray L. The role of clinical and social cognitive variables in parasuicide. Br J Clin Psychol 2006; 45: 465-81.

22 Scheier MF, Carver CS, Bridges MW. Distinguishing optimism from neuroticism (and trait anxiety, self-mastery, and self-esteem): a re-evaluation of the Life Orientation Test. J Pers Soc Psychol 1994; 67: 1063-78.

23 Hewitt PL, Flett GL. Perfectionism in the self and social contexts: conceptualization, assessment, and association with psychopathology. J Pers Soc Psychol 1991; 60: 456-70.
24 Sullivan C, Arensman E, Keeley HS, Corcoran P, Perry IJ. Young People's Mental Health: A Report of the Results from the Lifestyle and Coping Survey. National Suicide Foundation, 2004.

25 SISA. Power and Calculating Confidence Intervals (http://www. quantitativeskills.com/sisa/statistics/omhlp.htm).

26 Zahl DL, Hawton K. Repetition of deliberate self-harm and subsequent suicide risk: long-term follow-up study of 11583 patients. Br J Psychiatry 2004; 185: 70-5.

27 Ystgaard M, Reinholdt NP, Husby J, Mehlum L. Deliberate self-harm in adolescents. Tidsskr Nor Laegeforen 2003; 123: 2241-5.

28 Centers for Disease Control. Attempted suicide among high school students - United States, 1990. MMWR Morb Mortal Wkly Rep 1991; 24: 633-5.

29 Fekete S, Voros V, Osvath P. Suicidal behaviour and psychopathology in adolescents: results of a self-report survey of 15 and 16 -year-old adolescent people in Hungary. Eur Neuropsychopharm 2004; S365.

30 Bjarnason T, Thorlindsson T. Manifest predictors of past suicide attempts in a population of Icelandic adolescents. Suicide Life Threat Behav 1994; 24: $350-8$.

31 Cheng AT, Hawton K, Lee CT, Chen TH. The influence of media reporting of the suicide of a celebrity on suicide rates: a population-based study. Int J Epidemiol 2007; 36: 1229-34.

32 Exeter DJ, Boyle PJ. Does young adult suicide cluster geographically in Scotland? J Epidemiol Community Health 2007; 61: 731-6.

33 Melhem NM, Brent DA, Ziegler M, lyengar S, Kolko D, Oquendo $M$, et al Familial pathways to early-onset suicidal behavior: familial and individual antecedents of suicidal behavior. Am J Psychiatry 2007; 164: 1364-70.

34 Brunstein Klomek A, Marrocco F, Kleinman M, Schonfeld IS, Gould MS Bullying, depression, and suicidality in adolescents. J Am Acad Child Adolesc Psychiatry 2007; 46: 40-9.

35 Spirito A, Esposito-Smythers C. Attempted and completed suicide in adolescence. Annu Rev Clin Psychol 2006; 2: 237-66. 